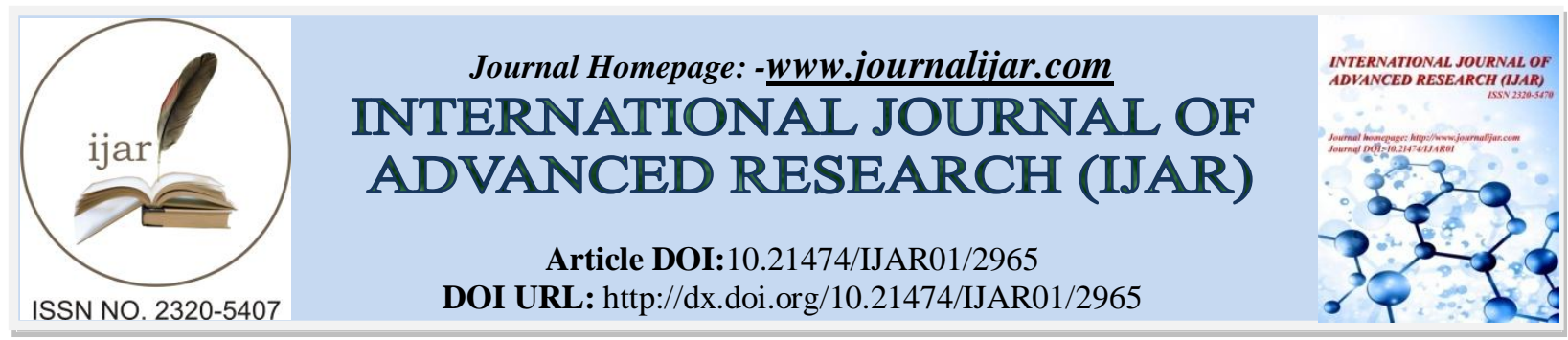

RESEARCH ARTICLE

\title{
KNOWLEDGE AND PRACTICE IN CHRONIC PAIN MANAGEMENT AMONGPRIMARY HEALTHCARE PHYSICIANS.
}

\author{
Saeed Muraya Alqahtani ${ }^{1}$, ShathaAwad Salman Alraddadi ${ }^{2}$, Rehab Abdullah Mohammad Almourey ${ }^{3}$, \\ Raghad Awad Salman Alradadi ${ }^{1}$, Ruba Awad Salman Alradadi ${ }^{1}$ and Wafaa Abdullah Aziz Al.Shehri ${ }^{1}$. \\ 1. Briman Primary Care center, Jeddah, Saudi Arabia . \\ 2. Madaen Fahad Primary care center, Jeddah, Saudi Arabia. \\ 3. King Abdulaziz University Hospital, Jeddah,Saudi Arabia.
}

\section{Manuscript Info}

[.........................

Manuscript History

Received: 30 November 2016

Final Accepted: 26 December 2016

Published: January 2017

Key words:-

Chronic Pain; Management; Primary

CarePhysicians; Practice, Confidence.

\section{Abstract}

Objective: To evaluatethe knowledge and practice in chronic pain management among primary healthcare physicians (PHCPs).

Methods: Across-sectional questionnaire-based study was carried out in a selected 15 primary healthcare centers in Jeddah, Saudi Arabiafrom October 15, 2016 to November 15, 2016.An auto-questionnaire was administered.The outcome measures included clinical practice score (CPS; range 20-100) and confidence level score (CLS; range 20-100).

Results:Physicians' practice showed a mean \pm SD (range) CPS $=76.13 \pm 15.12 \quad(41.11 ; 100.00)$. Most frequently assessed parameters included topography of the pain; followed by prior medications and physical impact. Less frequently assessed parameters included underlying cause, psychological impact and pain onset time.Frequent physical examinationsassessed the painful area; followed by general physical exam and inflammation signs. Less frequentexaminationsscreened for neuropathic pain component and motor and sensory abnormalities. Physicians in high patient-flow centers ( $\geq 30$ patients seen per day) had lower CPS. Physicians' confidence in chronic pain management showed a CLS $=69.60 \pm 16.61$ $(30.00 ; 100.00)$. Physicians declared being less confident of cancer chronic pain management,use of antidepressants, non-cancer chronic pain management,and use of anticonvulsant drugs. Higher CLS was reported in family physicians (CLS $=82.18 \pm 15.60$ ) as compared to pediatrics (73.50 \pm 14.09$)$ and general medicine (62.62 \pm 15.17$)$; $(\mathrm{p}=0.000001)$. CLS was proportional to age and experience.

Conclusion: Relatively insufficient practice and low levels of confidence among physicians regarding all aspects of chronic pain management was reported. Employing national or local protocols can be useful.

Copy Right, IJAR, 2016,. All rights reserved.

\section{Introduction:-}

Chronic pain is a common condition affecting $10 \%$ to $20 \%$ of the population across the world(Smith BHet al, 1999; Breivik Het al, 2006).It is associated with physical disability andpsychological, social and economic adverse 
effects(Breivik Het al, 2006, Gureje Oet al, 1998). Consequently, chronic pain is responsible for severe, multidimensional impact on patients' quality of life (Becker Net al, 1997). According to The International Association for the Study of Pain (IASP), pain is an unpleasant sensory and emotional experience associated with actual or potential tissue damage, or described by the patient in terms of such damage(IASP Taxonomy, 2014).Chronic pain is defined in more subjective terms, as a pain persisting beyond normal tissue healing time. Practically, it is admitted that pain persisting for 3 months or more indicates chronicity of the pain ( Upshur CC,et al 2006; Purves AM et al, 1998).

Ideal management of chronic pain requires careful assessment of the underlying causes, evolution, intensity along with sensory components to determine the type of pain, particularly neuropathic versus nociceptive pain. Additionally, it also demands the assessment of associated psychological, social and economic repercussions, which conditions the therapeutic approach Turk DC et al, 1987; Haanpää ML et al, 2009; Karoly and Jensen, 2013).

Despite the emergence of specialty pain management centers, majority of patients with pain complaints seek medical assistance in primary healthcare centers( Smith BHet al, 1999; Breivik Het al, 2006; Upshur CC, et al 2006). Pain is one of the most frequent complaints encountered in almost 1 in 2 patients attending primary healthcare centers(Mäntyselkä Pet al, 2001). This highlights the need for optimal knowledge of pain and the practice inchronic pain management among primary healthcare (PHC) providers, especially physicians.

On the other hand, assessment of practice in chronic pain management among family and primary healthcare physicians (PHCPs) showed unsatisfactory levels of knowledge,low therapeutic goalsand high prevalence of undertreated patients (Green CR et al, 2001; Ponte CD et al, 2005). Studies also showed that physicians areuncomfortable with the choice of drugs specified for the use in pain management especially with opioid analgesics, raising concerns about adverse effects, medication interactions and addiction, which often limits the prescribing of efficacious pain therapy (Bhamb Bet al, 2006; Von Roenn JHet al, 1993). This data highlightsthe lack of training and an urgent need for awareness among PHC providers.

Very few studies have assessed practice and knowledge about pain management in Saudi Arabia, majority of which were interested in nurses. This study showed a deficient knowledge, frequent misconceptions and inappropriate attitudesregarding assessment and treatment of pain. Need for training and national policies was highlighted (Eid Tet al, 2014; Kaki AMet al, 2009).

\section{Aim \& objectives:-}

This study aimedto evaluate the practice andself-assessed confidence level inchronic pain management among PHCPs in Jeddah, Saudi Arabia. Factors associated with good/bad practice and low/high confidence were explored.

\section{Methods:-}

A cross-sectional study was conducted among PHCPspracticing in selected PHC centersin Jeddah, Saudi Arabia. A semi-structured questionnaire was administered to participants, which was divided into 3 parts:

Demographic data including age, gender, marital status, years of practice, and specialty;in addition to average number of patients seen per day, approximate percentage of pain complaints, approximate percentage of patients suffering from chronic pain, and whether the participant or one of his close relatives suffered from chronic pain.

Assessment of practice in chronic pain including 4 sub-parts: practice in patient interview (12 items), physical examination (6 items), investigations (8 items) and therapy (11 items) in chronic pain. Each item is a 5-point likerttype scale assessing the frequency of the related practice ( $1=$ never, to $5=a$ always). A clinical practice score (CPS; range $=20$ to 90 ) was calculated for patient interview + physical exam practice part by adding scores of related items. This scorewas used as an indicator for complete level of the clinical assessment in chronic pain and was analyzed as an ordinal variable.

Self-rated confidenceregarding various aspects of chronic pain management (20 items); using 5-point likert-type scale ( $1=$ not confident; to $5=$ extremely confident). A confidence level score (CLS; range $=20$ to 100) wascalculated by adding the scores of theseitems and was analyzed a continuous variable. 
The questionnaire underwent face and content validity by authors and reliability was tested by calculation of the Cronbach's alpha for each relevant part.

\section{Sampling technique:-}

Participants (PHCPs)were recruited using a stratified two-stage cluster sampling method (Sedgwick P,2013). The city of Jeddah was divided into five sectors (strata); each containing 7 to 13 PHCs. ThreePHCs (clusters) wererandomly selected from each sector. A convenience sampling was used to include all physicians who were present at the participating PHC centers during the study period. Data was collected in an anonymous form.

The study was approved by the Medical Research and Studies Department, Directorate of Health Affairs - Jeddah, Ministry of Health.

\section{Statistical Methods:-}

Statistical analysis was performed with the Statistical Package for Social Sciences version 21.0 for Windows (SPSS Inc., Chicago, IL, USA). Categorical variables were presented as frequency and percentage; while both continuous and ordinal variables as mean \pm standard deviation (SD). Correlations were analyzed using independent $t$-test or OneWay analysis of variance (ANOVA) for continuous variables; chi-square test or Fisher's exact test for categorical variables; as appropriate; and nonparametric tests for ordinal variables. Significant factors of practice and confidence levels were analyzed as independent variables in linear regression analysis. A p-value $<0.05$ was considered for statistical significance.

\section{Results:-}

\section{Characteristics of the study population:-}

A total 124 PHCPs were included in the study.Of all the participants, $72.6 \%$ were females, $41.9 \%$ were aged between 30-39 years, 54.0\% were married, and 32.3\% had 0-5 years' professional experience. Regarding specialty, almost half of the participants $(49.2 \%)$ were general practitioners, $22.6 \%$ were family physicians and $12.9 \%$ were pediatricians. Participants reported a mean \pm SD number of patients $=38.89 \pm 26.89$ per day; among whom $41.09 \pm 25.80 \%$ were estimated to present with pain complaint and $23.24 \pm 19.42$ were estimated to suffer from chronic pain. Half $(50.0 \%)$ of the participants reported having personal or family history of chronic pain (Table 1).

Table 1. Characteristics of the population.

\begin{tabular}{|c|c|c|c|}
\hline Parameter & Category & Frequency & Percentage \\
\hline \multirow[t]{2}{*}{ Gander } & Male & 34 & 27.4 \\
\hline & Female & 90 & 72.6 \\
\hline \multirow[t]{5}{*}{ Age category (years) } & $20-29$ & 37 & 29.8 \\
\hline & $30-39$ & 52 & 41.9 \\
\hline & $40-49$ & 29 & 23.4 \\
\hline & $50-59$ & 5 & 4.0 \\
\hline & $60-69$ & 1 & 0.8 \\
\hline \multirow[t]{4}{*}{ Marital status } & Single & 52 & 41.9 \\
\hline & Married & 67 & 54.0 \\
\hline & Divorced & 5 & 4.0 \\
\hline & Widowed & 0 & 0.0 \\
\hline \multirow[t]{2}{*}{ Nationality } & Saudi & 104 & 83.9 \\
\hline & Non-Saudi & 12 & 9.7 \\
\hline \multirow[t]{4}{*}{ Years of practice (years) } & $0-5$ & 40 & 32.3 \\
\hline & $5-10$ & 48 & 38.7 \\
\hline & $10-15$ & 23 & 18.5 \\
\hline & $>15$ & 10 & 8.1 \\
\hline \multirow[t]{6}{*}{ Specialty } & General medicine & 61 & 49.2 \\
\hline & Family medicine & 28 & 22.6 \\
\hline & Pediatrics & 16 & 12.9 \\
\hline & Ob-gyn & 3 & 2.4 \\
\hline & Endocrinology & 1 & .8 \\
\hline & Internal medicine & 4 & 3.2 \\
\hline Number of patients per & Mean, SD & 38.89 & 26.89 \\
\hline
\end{tabular}




\begin{tabular}{|c|c|c|c|}
\hline day & Mean, SD & 41.09 & 25.80 \\
\hline $\begin{array}{c}\text { Approximate percentage } \\
\text { of patients presenting with } \\
\text { pain complaint }\end{array}$ & Mean, SD & 23.24 & 19.42 \\
\hline $\begin{array}{c}\text { Estimated percentage of } \\
\text { PHC patients suffering } \\
\text { from chronic pain }\end{array}$ & & 62 & 50.0 \\
\hline $\begin{array}{c}\text { Personal of family history } \\
\text { of chronic pain }\end{array}$ & Frequency, percentage & & \\
\hline
\end{tabular}

\section{Assessment of practice in chronic pain:-}

Analysis of reliability of part 2 of the questionnaire assessing PHCPs practice showed an excellent Cronbach's alpha $=0.933$ (37 items). Reliability of clinical practice part (interview + physical examination) was even better (18 items; Cronbach's alpha $=0.964$ ).

Assessment of overall clinical practice showed mean \pm SD (range) CPS $=76.13 \pm 15.12$ (41.11; 100.00). Assessment of patient's interview practice in chronic pain management showed moderate scores for all 12 interview items. On a scale from $1=$ never to $5=$ always, the most frequently assessed parameter during interview of patient with chronic pain was topography of the pain including localization and irradiations (mean \pm SD score $=3.98 \pm 0.91$ ), followed by prior medications (3.97 \pm 0.85$)$ and physical impact such as disability, sleep disturbance, etc. (3.96 \pm 0.84$)$. Whereas less frequently assessed parameters included underlying cause (3.84 \pm 1.11$)$,psychological impact $(3.78 \pm 0.99)$ and pain onset time (3.70 \pm 1.33$)$ (Figure 1).

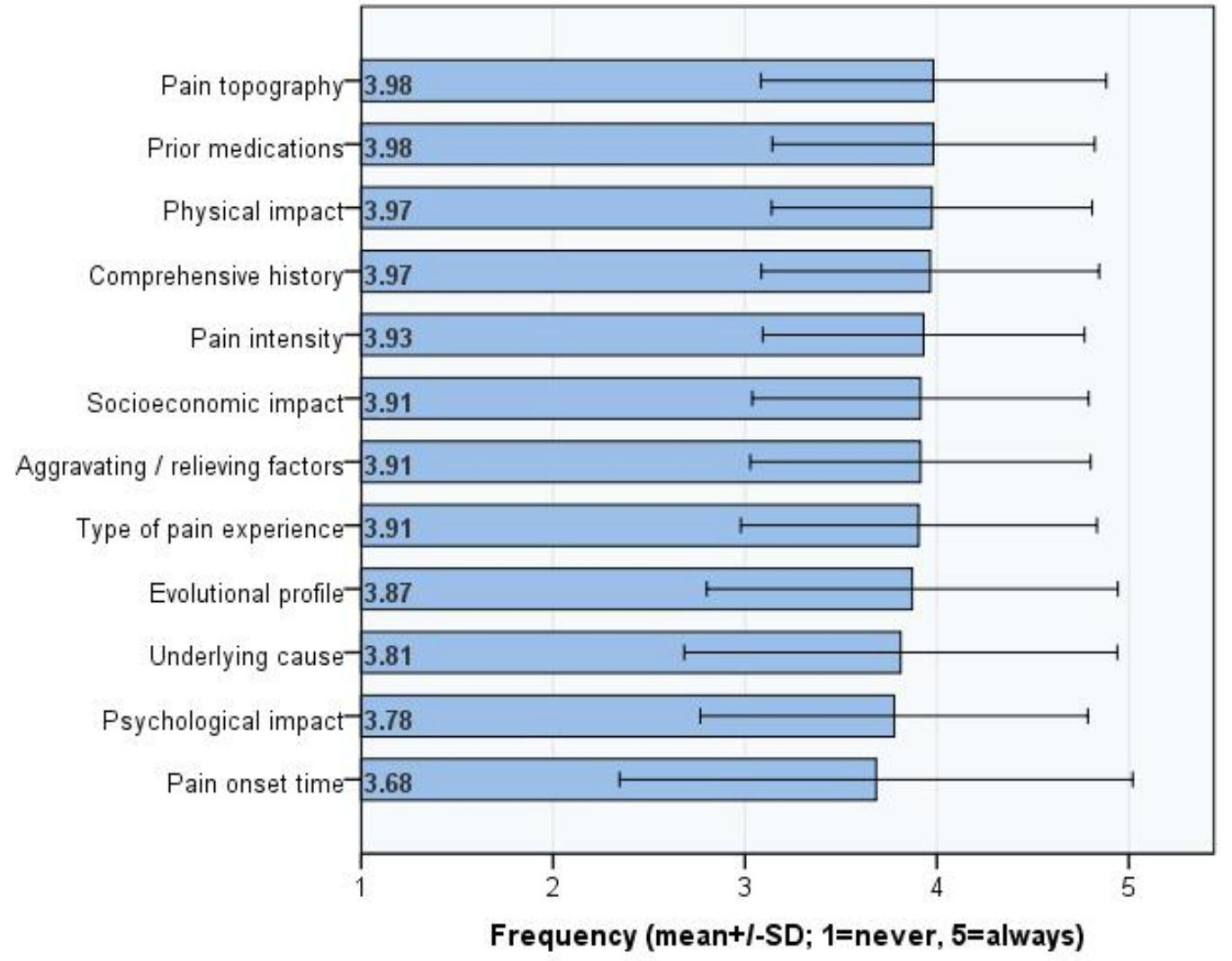

Figure 1:- Assessment of patient's interview practice in chronic pain management among primary healthcare physicians.

Physicians replied to the following question: "When receiving a patient with a chronic pain, how often do you perform each of the following actions?". Possible answers were: 1=never; 2=rarely; 3=sometimes; 4=often; $5=$ always. Bars represent mean \pm SD frequency in each item. 
Assessment of physical examination practice showed that the most frequently carried out examination was careful examination of the painful area (mean $\pm \mathrm{SD}=3.93 \pm 0.78$ ), followed by general physical exam $(3.69 \pm 0.86)$ and evaluation of inflammation signs $(3.66 \pm 0.98)$. The least carried out examinations included the screening for neuropathic component of the pain $(3,54 \pm 096)$, use of VAS to grade pain severity $(3.53 \pm 1.00)$ and screening for motor and sensory abnormalities (3.49 \pm 1.02$)$ (Figure 2).

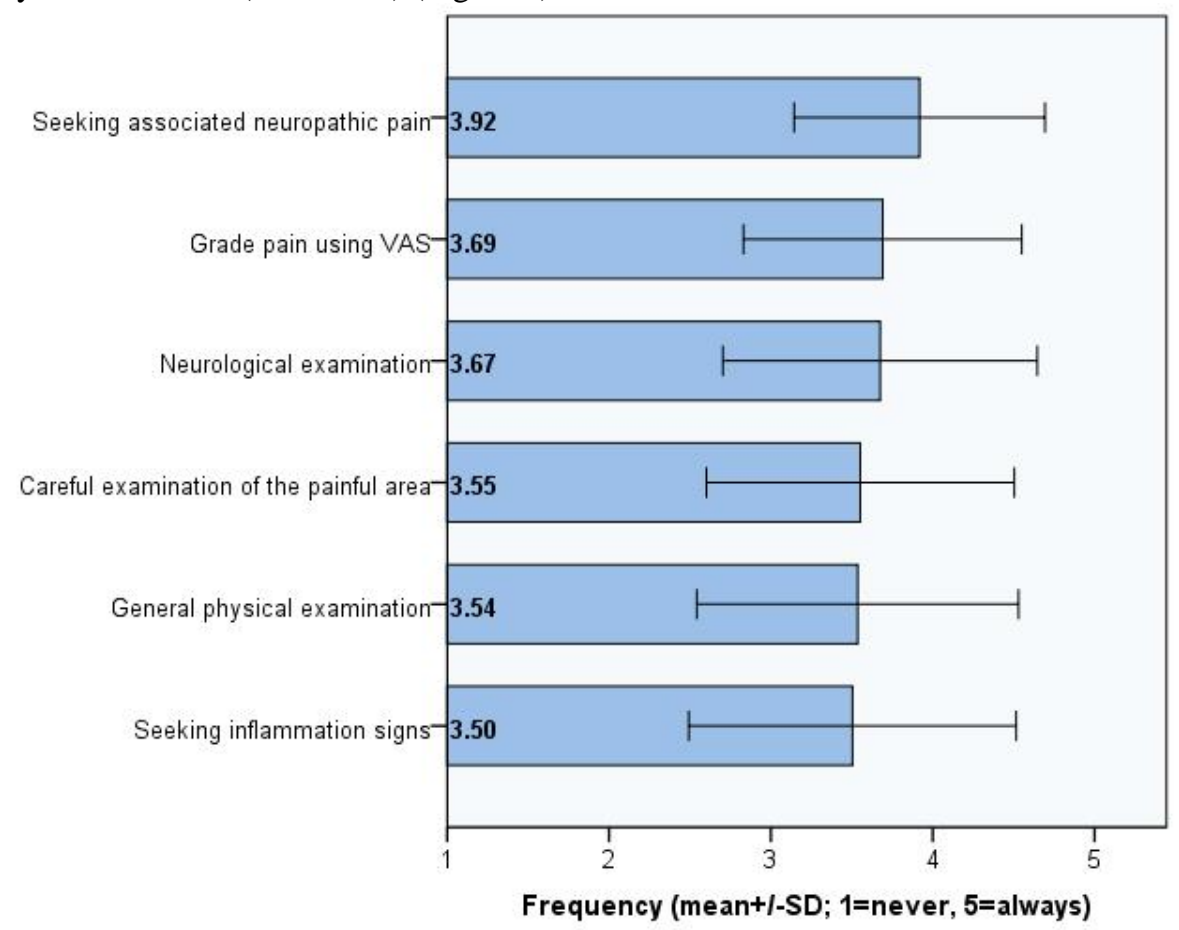

Figure 2:- Assessment of physical examination practice in chronic pain management among primary healthcare physicians.

Physicians replied to the following question: "When receiving a patient with a chronic pain, how often do you perform each of the following actions?" Possible answers were: 1=never; 2=rarely; 3=sometimes; 4=often; $5=$ always. Bars represent mean \pm SD frequency in each item. Regarding paraclinical and therapeutic practice in chronic pain management, PHCPs replied by yes/no to the question - "Have you ever prescribed the following for patients with chronic pain?"Analysis showed that the most frequently prescribed paraclinical investigations in chronic pain were x-rays and ultrasound of the painful zone (74.2\% and $67.7 \%$ respectively), followed by MRI and inflammatory marker $(62.1 \%)$ each. The most frequently prescribed treatments for chronic pain were non-steroidal anti-inflammatory drugs (NSAIDs), which were reported by $82.3 \%$ of the PHCPs, followed by muscle relaxants (65.3\%), non-opioid analgesics (64.5\%) and steroids (63.7\%); whereas antidepressants, anticonvulsant drugs. Psychotherapy was only reported by $43.5 \%, 46.0 \%$ and $48.4 \%$ of the PHCPs, respectively (Table 2). 
Table 2:- Assessment of paraclinical and therapeutic practice in chronic pain management among primary healthcare professionals.

\begin{tabular}{|c|c|c|}
\hline Practice & Frequency & Percentage \\
\hline Paraclinical investigations & & 74.2 \\
\hline X-rays imaging for the painful zone & 92 & 67.7 \\
\hline Ultrasound / Echography for the painful region & 84 & 54.4 \\
\hline CT Scanner & 67 & 62.1 \\
\hline Magnetic Resonance Imaging (MRI) & 77 & 58.1 \\
\hline Electromyogram & 72 & 62.1 \\
\hline Inflammatory markers & 77 & 57.3 \\
\hline Psychiatric evaluation & 71 & 25.0 \\
\hline Others & 31 & \\
\hline Therapy Prescribing & & 64.5 \\
\hline Non-opioid analgesics & 80 & 82.3 \\
\hline Steroids & 102 & 63.7 \\
\hline Opioid analgesics & 79 & 60.5 \\
\hline Non-steroid anti-inflammatry drugs (NSAIDs) & 75 & 46.0 \\
\hline Antidepressant drugs & 57 & 43.5 \\
\hline Muscle relaxants & 54 & 65.3 \\
\hline Physical therapy / Rehabilitation & 81 & 54.0 \\
\hline Psychotherapy & 67 & 48.4 \\
\hline Referral to specialist pain clinic & 60 & 62.1 \\
\hline Others & 77 & 12.1 \\
\hline
\end{tabular}

Participants replied to the question: have you ever prescribed the following for patients with chronic pain? "Yes" answers were reported in the Table.

\section{Assessment of confidence in chronic pain management:-}

Analysis of reliability of part 3 of the questionnaire assessing PHCPs confidence showed an excellent Cronbach's alpha $=0.948$ (20 items).

Assessment of physicians' confidence in chronic pain management showed a mean \pm SD (range) CLS $=69.60 \pm 16.61$ $(30.00 ; 100.00)$. Per-item assessments showed relatively higher confidence regarding the use of NSAIDs (mean \pm SD score $=3.82 \pm 0.96$ ), the assessment of pain severity (3.80 \pm 1.05$)$, knowledge about different types of chronic pain (3.77 \pm 1.00$)$ and assessment of impact of chronic pain on QOL (3.77 \pm 1.04$)$. Participants declared being relatively less confident regarding cancer-related chronic pain management (mean \pm SD score $=3.07 \pm 1.31$ ), use of antidepressants in chronic pain (3.19 \pm 1.19$)$, non-cancer chronic pain management (3.20 \pm 1.39$)$, and use of anticonvulsant drugs $(3.20 \pm 1.21)$ (Figure 3). 


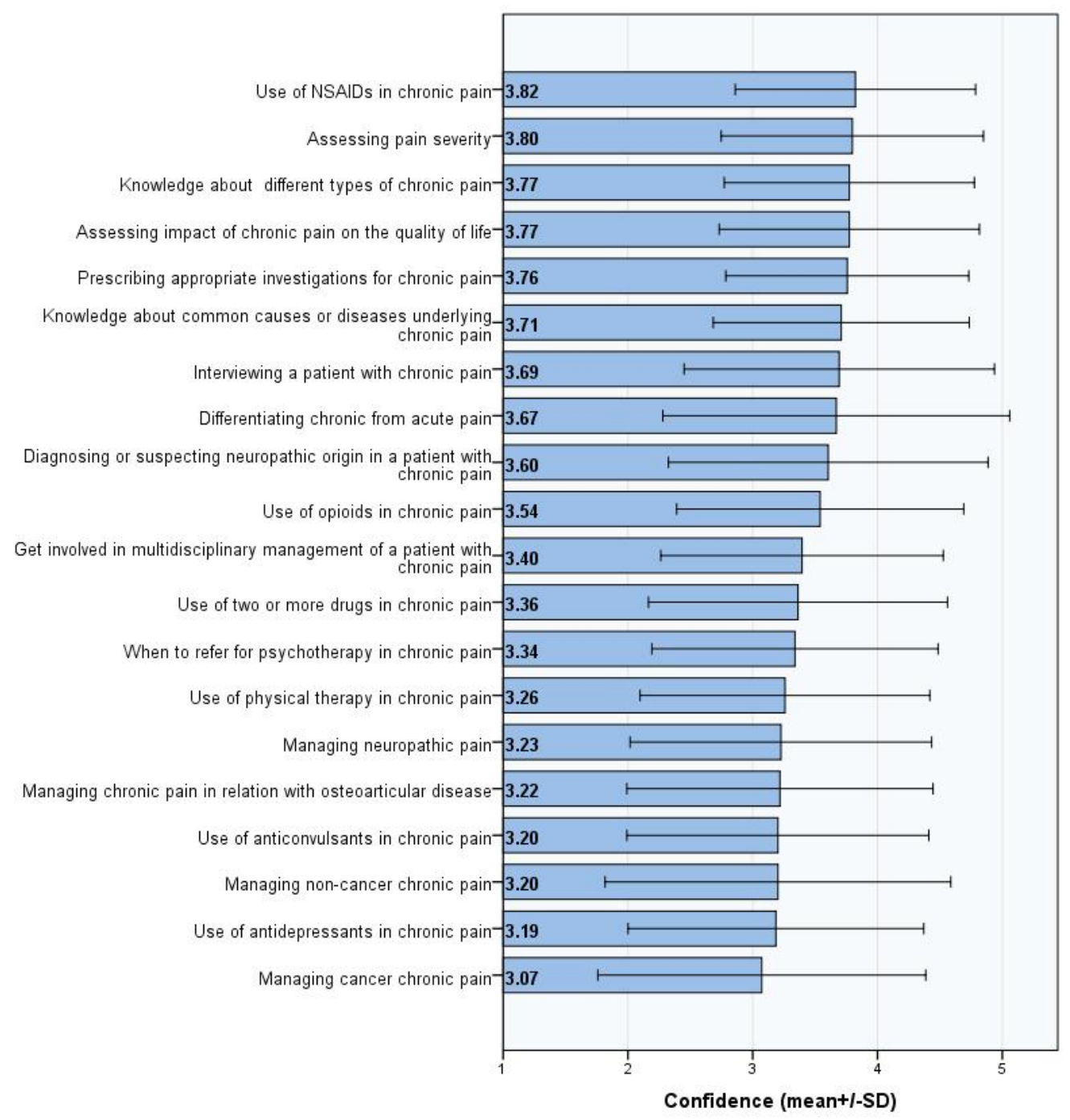

Figure 3:- Assessment of physician's confidence in chronic pain management.

Physicians replied to the following question: "How confident do you feel performing the following actions?" Possible answers were: $1=$ not confident; $2=$ not too confident; $3=$ confident; $4=$ very confident; $5=$ extremely confident. Bars represent mean \pm SD confidence level in each item.

Factors associated with practice and confidence in chronic pain management:-

When compared between male and female PHCPs, the female PHCPs had better practice indicators than male PHCPs with mean \pm SD CPS $=78.28 \pm 14.27$ versus $70.42 \pm 16.02 ; \mathrm{p}=0.009$, respectively. Participants who work in high patient-flow centers/services ( $\geq 30$ patients seen per day) had lower CPS as compared to those who work in low patient-flowservices (mean $\pm \mathrm{SD}$ ) $\mathrm{CPS}=72.52 \pm 15.26$ versus $82.24 \pm 12.89 ; \mathrm{p}=0.000422$, respectively. However, no significant difference in practice was observed across age categories $(0=0.062)$; marital status $(\mathrm{p}=0.453)$; years of practice $(\mathrm{p}=0.388)$; and specialty $(\mathrm{p}=0.117)$; or between physicians who had personal or family history or chronic pain and those who had not $(\mathrm{p}=0.202)$.

Regarding confidence, CLS was proportional to PHCPs age ( $\mathrm{p}=0.000025)$ and years of practice $(\mathrm{p}=0.022)$, and was higher in family physicians (mean \pm SD CLS $=82.18 \pm 15.60$ ) as compared with other specialties such as pediatrics (73.50 \pm 14.09$)$ and general medicine $(62.62 \pm 15.17)$; $(\mathrm{p}=0.000001)$. Confidence was also higher in physicians with personal of family history of chronic pain $(\mathrm{p}=0.013)$, as well as in physicians working in low patient-flow centers 
( $<30$ patients per day) as compared with their counterparts $(\mathrm{p}=0.006)$. However, no statistical difference was reported between the genders regarding confidence $(\mathrm{p}=0.804)$ (Table 3$)$.

Table 3:- Factors associated with low confidence and poor practice in chronic pain management among primary care physicians

\begin{tabular}{|c|c|c|c|c|c|c|c|}
\hline \multirow[t]{2}{*}{ Factor } & \multirow[t]{2}{*}{ Category } & \multicolumn{3}{|c|}{ Practice (CPS) } & \multicolumn{3}{|c|}{ Confidence (CLS) } \\
\hline & & Mean & SD & p-value & Mean & SD & p-value \\
\hline \multirow{2}{*}{ Gander } & Male & 70.42 & 16.02 & \multirow{2}{*}{$.009 *$} & 69.00 & 14.75 & \multirow[t]{2}{*}{.804} \\
\hline & Female & 78.28 & 14.27 & & 69.83 & 17.32 & \\
\hline \multirow{4}{*}{$\begin{array}{l}\text { Age category } \\
\text { (years) }\end{array}$} & $20-29$ & 74.02 & 14.31 & \multirow[t]{4}{*}{.062} & 63.49 & 15.17 & \multirow[t]{4}{*}{$.000025^{*}$} \\
\hline & $30-39$ & 76.99 & 13.14 & & 69.08 & 16.41 & \\
\hline & $40-49$ & 74.18 & 18.28 & & 72.72 & 14.10 & \\
\hline & $\geq 50$ & 91.11 & 13.79 & & 96.83 & 6.40 & \\
\hline \multirow[t]{3}{*}{ Marital status } & Single & 74.51 & 14.01 & \multirow[t]{3}{*}{.453} & 64.88 & 15.90 & \multirow[t]{3}{*}{$.009 *$} \\
\hline & Married & 76.93 & 16.33 & & 72.27 & 16.46 & \\
\hline & Divorced & 82.22 & 5.98 & & 83.00 & 12.39 & \\
\hline \multirow{4}{*}{$\begin{array}{l}\text { Years of practice } \\
\text { (years) }\end{array}$} & $0-5$ & 74.67 & 14.10 & \multirow[t]{4}{*}{.388} & 65.40 & 16.07 & \multirow[t]{4}{*}{$.022 *$} \\
\hline & $5-10$ & 77.91 & 11.09 & & 69.94 & 16.26 & \\
\hline & $10-15$ & 72.80 & 19.79 & & 70.22 & 15.12 & \\
\hline & $>15$ & 80.56 & 23.39 & & 83.30 & 18.23 & \\
\hline \multirow[t]{4}{*}{ Specialty } & General med. & 74.77 & 12.77 & \multirow[t]{4}{*}{.117} & 62.62 & 15.17 & \multirow[t]{4}{*}{$.000001 *$} \\
\hline & Family med. & 81.94 & 15.57 & & 82.18 & 15.60 & \\
\hline & Pediatrics & 78.89 & 15.60 & & 73.50 & 14.09 & \\
\hline & Others & 82.08 & 15.96 & & 79.13 & 12.80 & \\
\hline \multirow{2}{*}{$\begin{array}{l}\text { Personal or } \\
\text { family history of } \\
\text { chronic pain }\end{array}$} & No & 78.13 & 11.18 & \multirow[t]{2}{*}{.202} & 65.75 & 18.35 & \multirow[t]{2}{*}{$.013 *$} \\
\hline & Yes & 74.62 & 17.62 & & 73.32 & 14.14 & \\
\hline \multirow{2}{*}{$\begin{array}{l}\text { Average number } \\
\text { of patients per } \\
\text { day }\end{array}$} & $<30$ & 82.24 & 12.89 & \multirow[t]{2}{*}{$.000422 *$} & 74.89 & 15.81 & \multirow[t]{2}{*}{$.006^{*}$} \\
\hline & $\geq 30$ & 72.52 & 15.26 & & 66.49 & 16.36 & \\
\hline
\end{tabular}

CPS: Clinical practice score; CLS: confidence level score; * Statistically significant result $(\mathrm{P}<0.05)$; med.: Medicine.

Correlation between confidence and practice:-

Linear regression analysis showed a positive correlation between confidence and practice in chronic pain management, with a weak correlation coefficient ( $\mathrm{r}=0.397$; odds-ratio $[\mathrm{OR}]=1.43$; 95\% CI: 1.24 to 1.67 ; $\mathrm{p}=0.000005$ ), (Figure 4).

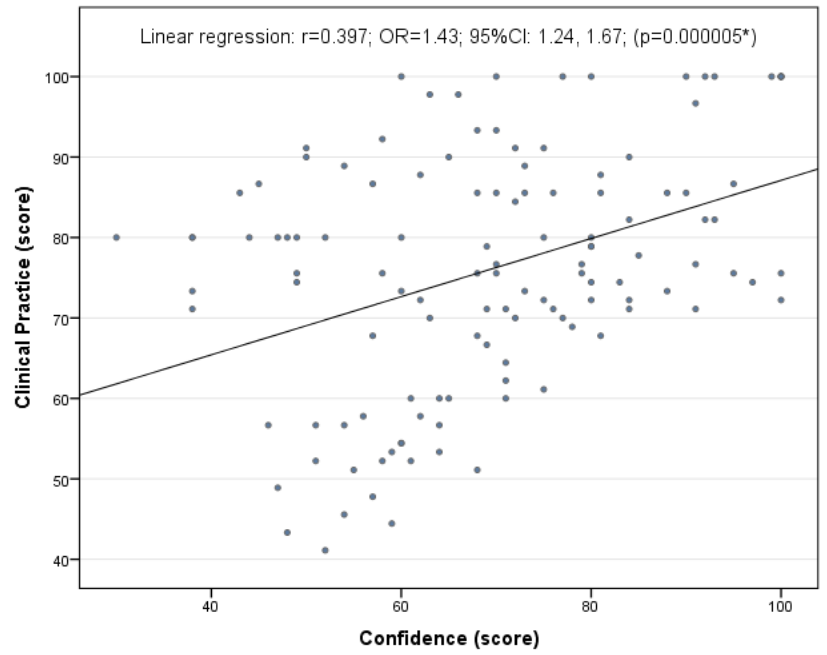

Figure 4:- Correlation between confidence and practice in chronic pain management among primary healthcare physicians. 


\section{Discussion:-}

This study highlighted the insufficient practice and relatively low confidence in chronic pain management among PHCPs. The calculated scores including CPS and CLS were used as an indicator of the quality of clinical practice and self-assessed confidence of physicians in chronic pain management respectively. Results showed an unsatisfactory practice as well as the confidence. These resultsmay reflect a lack of training among PHCPsalong with a weak implementation of pain specialized healthcare chain. Comparable observations were reported in the USA, where patients' access to pain specialized centers isstill inadequatedue to lack of optimal training among healthcare professionals and uncoordinated interdisciplinary management. These results indicatethe frequent undertreatment among patients and unmet needs for care within the society (Dubois and Follett, 2014). Studies from Europe estimated that 1 in 2 patients with chronic pain have inadequate management of their condition ( ${ }^{\mathrm{a}}$ Breivik $\mathrm{H}$, 2006; 'Breivik H, 2012). On the other hand, pain management has recently emerged as a subspecialty. Therefore, cultural changes should be operated, both among patients and health professionals, to promote proper understanding of chronic pain, its related factors and specific assessment and the treatment aspects (Medicine Io, 2011).

Regarding clinical assessment, item-specific analysis demonstrated that physicians often failed to investigate theimportant features ofchronic painthrough patient's interview and physical examination, which further resulted in insufficient diagnosis and poor treatment decisions. For example, failure to explore psychological impact of chronic pain exposes the physician tothe risk of missingthe diagnosisof an adjacent psychiatric disorders such as anxiety or depression, which is highly associated with impaired quality of life and compromises management and therapeutic outcomes (Kroenke Ket al, 2013). The prevalence of depression in relation to chronic pain is higher than in the general population and was reported to be as high as $21 \%$. In addition, patients suffering from chronic pain are highly exposed to social and professional exclusion ( ${ }^{\mathrm{a} B r e i v i k ~ H, ~ 2006 ; ~}{ }^{\mathrm{b}}$ Breivik H, 2012). Psychosocial aspects constitute a major concern in chronic pain management and should be integrated in the treatment goals by promoting patient's rehabilitation and improving quality of life(Mills Set al, 2016).

Participants estimated that approximately $25 \%$ of their patients suffered from chronic pain, which is as high as the prevalence reported in the general population (McQuay and Moore, 2008). Such a high prevalence makes chronic painbecome a burdensomepublic health issue, both medically and economically (Nahin RL, 2015; Gaskin and Richard,2012). Studies have demonstrated that patients with chronic pain have increased mortality and cardiovascular morbidity, and frequently associated multi-pathological conditions(Guthrie B et a 2012; Barnett Ket $\mathrm{al}, 2012$ ). The existence of such comorbidities often limits pain management and restricts the use of efficacious therapeutic options.Consequently, PHCPsshould be aware and attentive about the necessity of a comprehensive approach in the management of chronic pain as majority of these patients are exclusively managed in primary care; elicit considerable care resources and have greater use of emergency serviceswhile only a minority are referred to secondary care ( ${ }^{\mathrm{a} B r e i v i k} \mathrm{H}$ et al,2006; Briggsl E Vet al 2011; McLeod and Nelson, 2013; Anderson Det al, 2012).

Confidence in the use of opioidsin chronic pain management was relatively low as compared to that in use of NSAIDs. The use of opioid analgesics is often limited by physicians' misconception and apprehensive attitude evoking concerns about medication misuse, addiction risk among patient and insufficient training (Canada REet $\mathrm{al}, 2014$; Jamison $\mathrm{RN}$ et al,2014). This attitude exposes to an odd risk of undertreatment among patients with chronic pain and engenders unsatisfactory results. Adequate trainings on opioids use and misuse risk assessment should be proposed to PHCPs to improve their knowledge and confidence and to also dissipate their apprehensions and change their attitude towards the use of opioids in primary care for chronic pain (Kavukcu E et al 2015). Also, physicians should be trained on ways to assess the patients' benefits from opioids and how to ensure that the risks justify the benefits to boost their confidence in the use of these agents (Frank JW et al, 2014).

In addition, prescribing guidelines and protocols should be implemented to support the therapeutic decision making in chronic pain and to ensure better adherence to good practice (Canada RE et al, 2014). However, several other aspects in prescribing opioids should be taken into consideration, including availability, cost and form of the medication (transdermal, sublingual, etc.), in addition to individual tolerability, compliance and efficacy profiles requiring personalized titration and dosage techniques ( Pergolizzi J et al, 2008).

Considering other aspects of physical examination, participants reported frequentexamination for neuropathic pain in patients with chronic pain, while underlying cause of pain is less frequently sought. Neuropathic pain, as opposed to nociceptive pain, results from damageor dysfunction of nerve fibers responsible for abnormal pain perception. It is a frequent condition encountered in up to $17 \%$ of cases of chronic pain and has been reported to be on the rise in 
the last decade (Frank JW et al,2014). It may be associated to specific syndromes, such as diabetic peripheral neuropathy, postherpetic neuralgia, trigeminal neuralgia and low-back pain with spinal disorders( Boogaard $\mathrm{S}$ et al, 2015; van Hecke Oet al, 2014; Yamashita Tet al,2014). It is generally associated with greater impact on quality of life(Hiyama A et al, 2015). Several screening tools have been developed for clinical detection of neuropathic pain, such as the Neuropathic Pain Diagnosis Questionnaire (DN4)and the Neuropathic Pain Questionnaire (NPQ) which are reliable and simple to use in routine practice ( Haanpää ML et a, 2009).

Female gender and low workload ( $<30$ patients per day) were the only two favorable factors for good clinical practice in chronic pain management, including an adequate patient's interview and physical examination. The other factors such asage, years of practice and specialty had no effect on the practice. However, increased confidence level was associated with age and years of practice and was higher in family physiciansas compared to their counterparts. In addition, the existence of a personal or family history of chronic pain increased the confidence but did not improve clinical practice.Overall quality of practice showed weak correlation with confidence level in linear regression $(\mathrm{r}=0.397)$.

This data suggests that, beyond insufficient knowledge and confidence, a lack of awareness and investment exist among PHCPs in the management of chronic pain. Corrective measures should be undertaken to promote interest and good clinical practice in pain management among PHCPs.

\section{Conclusion:-}

This study explored chronic pain management in PHC centers of Jeddah and revealed insufficient practice and low levels of confidence among physicians regardingdifferentaspects of chronic pain management. Although physicians' confidence increased with age and experience and was shown to be higher in family physicians, the level of practice remains comparably inappropriate.

The correlation between confidence and practice indicates the importance of enhancing knowledge about chronic pain management by the means of training and increase of clinical exposure among physicians to improve their practice.However, the weak correlation coefficient suggests the existence of other adverse factors for good practice, such as a lack of awareness or investment, which requires the implementation of awareness raising strategy. The implementation of national guidelines and or local protocols can be useful in prompting physicians' confidence and improving physicians' adherence to good practice, especially regarding specific aspects such as opioids use, diagnosis and treatment of neuropathic pain and assessment and management of multi-dimension impact of chronic pain on patient's quality of life.

\section{Acknowledgment:-}

We are grateful to the Directorate of Health Affairs - Jeddah and to all participating primary health care centers for their kind support in the realization of this study. We also thanks Dr. Mohamed Amine HAIRECHE for his support in the preparation of the manuscript.

\section{References:-}

1. Green CR, Wheeler JRC, Marchant B, LaPorte F, Guerrero E. (2001): Analysis of the physician variable in pain management. Pain Med. Wiley Online Library., 2(4):317-27.

2. Gureje O, Von Korff M, Simon GE, Gater R. (1998): Persistent pain and well-being: a World Health Organization study in primary care. Jama American Medical Association., 280(2):147-51.

3. Guthrie B, Payne K, Alderson P, McMurdo MET, Mercer SW. (2012): Adapting clinical guidelines to take account of multimorbidity. Br Med J. BMJ Publishing Group.,345(oct04):e6341--e6341.

4. Haanpää ML, Backonja M-M, Bennett MI, Bouhassira D, Cruccu G, Hansson PT, et al. (2012): Assessment of neuropathic pain in primary care. Am J Med. Elsevier., 122(10):S13--S21.

5. Hiyama A, Watanabe M, Katoh H, Sato M, Sakai D, Mochida J. (2015): Evaluation of quality of life and neuropathic pain in patients with low back pain using the Japanese Orthopedic Association Back Pain Evaluation Questionnaire. EurSpine J [Internet]., 14;24(3):503-12. Availablefrom: http://link.springer.com/10.1007/s00586-014-3723-y

6. International Association for the Study of Pain (IASP). (2014): IASP Taxonomy [Internet].,Available from: http://www.iasp-pain.org/Taxonomy 
7. Jamison RN, Sheehan KA, Scanlan E, Matthews M, Ross EL. (2014): Beliefs and attitudes about opioid prescribing and chronic pain management: survey of primary care providers. J Opioid Manag [Internet]., 10(6):375-82. Available from: http://www.ncbi.nlm.nih.gov/pubmed/25531955

8. Kaki AM, Daghistani MF, Msabeh AA. (2009); Nurses' knowledge of pharmacological measures on acute pain management in Western Saudi Arabia. Saudi Med J., 30(2):279-83.

9. Karoly P, Jensen MP. (2013) Multimethod Assessment of Chronic Pain: Psychology Practitioner Guidebooks. Elsevier.

10. Kavukcu E, Akdeniz M, Avci HH, Altuğ M, Öner M.(2015): Chronic noncancer pain management in primary care: family medicine physicians' risk assessment of opioid misuse. Postgrad Med [Internet]., 127(1):22-6. Available from: http://www.ncbi.nlm.nih.gov/pubmed/25539797

11. Kroenke K, Outcalt S, Krebs E, Bair MJ, Wu J, Chumbler N, et al. (2013): Association between anxiety, healthrelated quality of life and functional impairment in primary care patients with chronic pain. Gen Hosp Psychiatry [Internet]., 35(4):359-65. Available from: http://www.ncbi.nlm.nih.gov/pubmed/23639186

12. Mäntyselkä P, Kumpusalo E, Ahonen R, Kumpusalo A, Kauhanen J, Viinamäki H, et al. (2001): Pain as a reason to visit the doctor: a study in Finnish primary health care. Pain. Elsevier., Jensen 89(2):175-80.

13. McLeod D, Nelson K. (2013): The role of the emergency department in the acute management of chronic or recurrent pain. AustralasEmergNurs J. Elsevier., 16(1):30-6.

14. McQuay H, Moore R. (2008): Epidemiology of chronic pain. IASP Press. Seattle: IASP Press.

15. Medicine Io. (2011): Relieving Pain in America: A Blueprint for Transforming Prevention, Care, Education, and Research. Washington, DC: The National Academies Press.

16. Mills S, Torrance N, Smith BH. (2016): Identification and Management of Chronic Pain in Primary Care: a Review. Curr Psychiatry Rep [Internet]., 28;18(2):22. Available from: http://link.springer.com/10.1007/s11920015-0659-9

17. Nahin RL. (2015): Estimates of pain prevalence and severity in adults: United States, 2012. J Pain. Elsevier., 16(8):769-80.

18. Pergolizzi J, Böger RH, Budd K, Dahan A, Erdine S, Hans G, et al. (2008): Opioids and the management of chronic severe pain in the elderly: consensus statement of an International Expert Panel with focus on the six clinically most often used World Health Organization Step III opioids (buprenorphine, fentanyl, hydromorphone, met. Pain Pract [Internet]., 8(4):287-313. Available from: http://www.ncbi.nlm.nih.gov/pubmed/18503626

19. Ponte CD, Johnson-Tribino J. (2005): Attitudes and knowledge about pain: An assessment of West Virginia family physicians. In: Family Medicine., p. 477-80.

20. Purves AM, Penny KI, Munro C, Smith BH, Grimshaw J, Wilson B, et al. (1998): Defining chronic pain for epidemiological research-assessing a subjective definition. Pain Clin. VSP BV PO BOX 346, 3700 AH ZEIST, NETHERLANDS., 10(3):139-47.

21. Sedgwick P. (2013): Stratified cluster sampling. BMJ. British Medical Journal Publishing Group., 347:f7016.

22. Smith BH, Hopton JL, Chambers WA. (1999): Chronic pain in primary care. Fam Pract. Oxford Univ Press., 16(5):475-82.

23. Turk DC, Rudy TE. (1987) Towards a comprehensive assessment of chronic pain patients. Behav Res Ther [Internet]., 25(4):237-49. Available from: http://linkinghub.elsevier.com/retrieve/pii/0005796787900027

24. Upshur CC, Luckmann RS, Savageau JA. (2006): Primary care provider concerns about management of chronic pain in community clinic populations. J Gen Intern Med. Wiley Online Library., 21(6):652-5.

25. vanHecke O, Austin SK, Khan RA, Smith BH, Torrance N. (2014): Neuropathic pain in the general population: A systematic review of epidemiological studies. Pain [Internet].155(4):654-62. Available from: http://content.wkhealth.com/linkback/openurl?sid=WKPTLP:landingpage\&an=00006396-201404000-00004

26. Von Roenn JH, Cleeland CS, Gonin R, Hatfield AK, Pandya KJ. (1993): Physician attitudes and practice in cancer pain management: a survey from the Eastern Cooperative Oncology Group. Ann Intern Med. Am CollPhysicians.119(2):121-6.

27. Yamashita T, Takahashi K, Yonenobu K, Kikuchi S. (2014): Prevalence of neuropathic pain in cases with chronic pain related to spinal disorders. J OrthopSci [Internet]. 19(1):15-21. Available from: http://linkinghub.elsevier.com/retrieve/pii/S0949265815303560 